\title{
RELAÇŐES SOCIAIS ENTRE A EQUIPE DE ENFERMAGEM E PAIS DE CRIANÇAS HOSPITALIZADAS *
}

\author{
Edelia del Pilar Neira Huerta** \\ Lélia Maria Madeira** \\ Matilde Meire Miranda** \\ Telma Ribeiro Garcia**
}

NEIRA HUERTA, E. del P.; MADEIRA, L.M.; MIRANDA, M.M.; GARCIA, T.R. Relações sociais entre a equipe de enfermagem e pais de crianças hospitalizadas. Rev. Esc. Enf. USP, São Paulo, 20(1):55-69, 1986.

Utilizando a entrevista semi-estruturada e a observação assistemática, as autoras procuram identificar os tipos de relações sociais que ocorrem entre a equipe de enfermagem $e$ os pais na visita à criança hospitalizada.

\section{INTRODUÇÃO}

A liteuratura sobre a problemática da criança hospitalizada tem sido favorável à presença dos pais junto à criança. Entretanto, a atmosfera hospitalar estranha, o linguajar técnico, quase sempre incompreensivel para os leigos, utilizado no hospital para descrever as condições da criança, o sentimento de culpa e/ou o medo de serem responsabilizados pela doença do filho, entre outras causas, fazem com que os pais percam a auto confiança no cuidado do filho e evidenciem comportamentos de ansiedade.

Para BRIGHT ${ }^{1}$, a enfermeira pode dar apoio e aumentar a auto confiança da mãe, estabelecendo relacionamento caracterizado, principalmente, pela aceitação da ansiedade da mãe como fenômeno natural e pela participação desta no cuidado da criança.

ROY $^{2}$ idealizou um método, que denominou P.I.P., para integrar as mães no papel que devem assumir durante a visita aos filhos hospitalizados. Segundo este método, a enfermeira deveria:

P - prestar atenção ao foco de atenção das mães;

I - informá-las sobre a situação atual da criança;

$\mathrm{P}$ - permitir a participação das mães nos cuidados à criança.

Segundo SMITHERMAN ${ }^{3}$, identificar as emoções, atitudes, medos e preocupações dos pais seria uma forma de se ajudar a criança, pois

* Trabalho apresentado a disciplina Fundamentos Palcossocials da Enfermagem do Curso de Pós-Graduação em Enfermagem, nível mestrado, de Escola de Enfermagem da USP.

** Aluna do Curso de Pós-Graduaç̆̃̃o, nível Mestrado, da Escola de Enfermagem da USP, 1982 
conforme é sabido, a ansiedade dos pais é transmitida aos filhos, influenciando desta forma na recuperação de sua saúde. Para essa autora, as necessidades dos pais são, entre outras: ver que seus filhos estão recebendo cuidados físicos competentes; compreender a condição médica e o tratamento de seus filhos; sentir que são importantes para seus filhos e capazes como pais; e ter oportunidade para discutir seus sentimentos sobre a hospitalização de seus filhos.

Entretanto, segundo temos observado, os pais não recebem a assistência de que necessitam. Sob a alegação de que as visitas tumultuam a enfermaria, atrapalham o andamento do serviço, contribuem para as infecções cruzadas, e de que as crianças ficam agitadas após a visita dos pais, a equipe de enfermagem tem dado pouca ou nenhuma atenção às reações dos pais à doença e à hospitalização de seus filhos.

\section{OBJETIVO}

Conscientes da problemática anteriormente delineada e da necessidade de uma ação que a modifique, propusemos, como objetivo para este trabalho, identificar os tipos de relações sociais que ocorrem entre a equipe de enfermagem e os pais na visita à criança hospitalizada.

\section{METODOLOGIA}

Para atender ao objetivo proposto, escolhemos como métodos, a observação e a entrevista semi-estruturada e como local, uma unidade pediátrica de um hospital-escola governamental.

Na primeira etapa do trabalho, expusemos à diretoria da divisão de enfermagem da instituição o objetivo de nosso estudo. Após obtermos sua autorização para a realização do trabalho, explicamos à enfermeira chefe da unidade que, durante dois dias, compareceriamos à unidade para observar o comportamento das mães e o relacionamento mãe-filho durante a visita. Com isto pretendíamos que não ocorressem modificações de comportamento da equipe de enfermagem a partir do conhecimento de nosso verdadeiro objetivo.

Obtivemos da enfermeira chefe a relação das crianças que eram visitadas regularmente e decidimos que as duas primeiras mães a chegarem para a visita seriam aquelas cujas relações sociais com a equipe de enfermagem iriam ser observadas. Foram então selecionados e observados:

- Caso 1 - P., 7 meses de idade, filho único de um casal residente em Peruíbe. Desde os 2 meses de idade apresenta problemas respiratórios, sendo esta sua terceira internação hospitalar. Tem diagnóstico de broncopneumonia e pneumopatia crônica. A mãe o visita diariamente e o pai, nos fins de semana. Criança no trigésimo dia de internação.

- Caso 2 - J., de 2 meses de idade. Transferida de outro hospital por «má-evolução» e cianose universal. Admitida com diagnóstico 
de broncopneumonia bilateral e atelectasia à esquerda. A mãe, de 20 anos, visita a criança cada 2 dias por ter de cuidar do filho mais velho ( 1 ano e 3 meses) e por problemas financeiros (SIC). Criança no vigésimo primeiro dia de internação.

$\mathrm{Na}$ segunda etapa do trabalho, foram realizadas entrevistas com duas mães e com a equipe de enfermagem: enfermeira chefe da unidade, enfermeira de unidade, auxiliar de enfermagem e atendentes de enfermagem que prestavam assistência às crianças das enfermarias em que observaçōes foram realizadas.

Para justificar a entrevista com a equipe de enfermagem dissemos que, a fim de complementar nossas observações, seria muito importante conhecer a opinião da equipe a respeito da visita.

A entrevista se desenvolveu a partir das seguintes questões:

a) para a equipe de enfermagem: - «O que representa para você a visita dos pais à criança hospitalizada?»

b) para as mães: - «Como se sente no hospital?». - «Como se sente em relação às pessoas que cuidam de seu filho?». — «Como se sente quando sai do hospital, após a visita?».

\section{DADOS OBTIDOS}

\section{DADOS OBTIDOS DAS OBSERVAÇÕES}

\section{Caso 1.}

1" observação: - data: 21 de setembro (terça-feira) 10h30m;

- local: enfermaria 2 (capacidade de 9 leitos);

- pessoal: 1 enfermeira, 1 auxiliar de enfermagem, 2 atendentes de enfermagem e 4 alunas de enfermagem.

10h35m - A mãe chega para visitar a criança, lava as mãos e aproxima-se, sorrindo para a criança; coloca-a no colo. Observa que a criança evacuou e diz para a auxiliar: «Está de cocô. Quero uma fralda para trocar».

Auxiliar (dirigindo-se à atendente) : «O P. está sujo de novo!»

A atendente aproxima-se para entregar uma fralda limpa.

Atendente: «Nossa! Tá imundo!»

A mãe não responde, limitando-se à higiene da criança.

$10 \mathrm{~h} 40 \mathrm{~m}$ - Coloca a criança no colo e leva-a para passear no corredor.

$10 \mathrm{~h} 48 \mathrm{~m}$ - Recoloca a criança no berço, cobre-a e fica ninando. Dirige-se à auxiliar: «Colheram sangue dele ontem .... » 
A auxiliar olha para a mãe e saindo em outra direção, responde: «Colheram?».

10h55m - A criança está um pouco dispnéica, em oxigenoterapia. A mãe debruçada sobre ela, acaricia-a.

$11 \mathrm{~h} 03 \mathrm{~m}$ - A atendente aproxima-se do berço com uma mamadeira de suco de laranja e coloca-a na boca de P., que não reage. Torna a colocar a mamadeira na boca da criança e sai sem olhar para a mãe ou falar com ela. A mãe apanha a mamadeira e tenta fazer com que $P$. sugue. Dirigindo-se às observadoras a mãe diz: «É suco de laranja; ele não gosta.» Comenta ainda que a médica do P. é a Dra. M.

11 h10m - A mãe olha o relógio; uma estudante de enfermagem se aproxima.

Estudante: «O P. agora está mais calmo.»

Mãe: «Ele tomou a mamadeira das oito?»

Estudante: «Ele não aceitou hoje, nem ontem.»

Mãe: «E a mamadeira das dez?»

A estudante não sabe responder. A mãe pergunta então ao atendente. Este, olhando o prontuário, informa que a criança tomou $60 \mathrm{ml}$. A mãe demonstra alívio.

$11 \mathrm{~h} 15 \mathrm{~m}$ - O atendente aproxima-se do berço, põe a mão no «bumbum» da criança e dirigi-se à mãe: «Ele não tomou suco?»

Mãe: «Não».

Atendente: «Ele não gosta.»

2: observação: - data: 23 de setembro (quinta-feira) 10h25m;

- pessoal: 1 enfermeira, 1 atendente de enfermagem e 1 auxiliar de enfermagem.

10h30m - A enfermeira, entrando na enfermaria, diz: «Quem perfumou o ambiente? Foi o P.?»

A mãe cheira o «bumbum» da criança e diz que não foi o $P$. e prepara a criança «para sair». No corredor, encontra uma estudante de enfermagem que brinca com a criança.

Estudante: «Como a senhora acha que ele está?»

Mãe: «Tá bem mais calmo.»

Estudante (observando P. levar o chocalho à boca): «Tá coçando o dente? A mãe responde: "Acho que não.»

A criança deixa o chocalho cair no chão; a estudante o apanha e diz à mãe que vai lavá-lo. Volta e o entrega à criança, sempre sorrindo.

10h45m - A enfermeira, da porta da enfermaria grita: «P., venha tomar remédio! Volte prá dentro de sua casa!» 
A mãe retorna à enfermaria com a criança. A auxiliar de enfermagem lhe pede dara deitar a criança e administra a medicação oral.

A mãe tenta acalmar a criança que se encontra agitada.

Auxiliar: «P., você não aprende?»

$10 \mathrm{~h} 50 \mathrm{~m}$ - A atendente se aproxima com a mamadeira de leite, diz:

«É do P., a mamadeira das dez horas.»

Mãe: (olhando o relógio e fazendo uma careta) : «Quase na hora do almoço.» Comenta, ainda, para si mesma: «A canseira dele não passa.»

11h - Entra a enfermeira chefe, comenta algo com a enfermeira e sai. e sai.

11h05m - A enfermeira chefe retorna, pergunta algo à enfermeira

A atendente se dirige à mãe: «Faz tempo que ele mamou?»

Mãe: «Mamou quase agora... $70 \mathrm{ml} . »$

A atendente leva a mamadeira.

11h15m - A mãe dirigindo-se às observadoras, comenta: «A unha tá gozada, parece que vai cair.» Conversa com as observadoras sobre a ansiedade do pai para visitar a criança, sobre as expectativas do casal durante a gravidez, de que nascesse um menino e que já tinham até escolhido o nome.

\section{Caso 2.}

1. observação: - data: 21 de setembro (terça-feira) $10 \mathrm{~h} 20 \mathrm{~m}$;

- local: enfermaria 3 (capacidade de 4 leitos); enfermagem.

- pessoal: 1 enfermeira, 1 auxiliar de enfermagem, 1 atendente de

10h20m - Criança em berço aquecido e tenda de oxigênio, com nutrição parenteral prolongada instalada em veia do couro cabeludo, e com sonda nasogástrica.

10h35m - A mãe entra na enfermaria, cumprimenta a atendente sorrindo, olha para a criança.

Atendente: «Ela está com uma carinha ótima hoje.»

A mãe faz menção de colocar a mão na criança, olha em volta, retira a mão.

Atendente: «Hoje ela aceitou um pouquinho pela boca.»

Mãe: (referindo-se à dieta endovenosa e por sonda): «Tomara que não precise mais... » 
Auxiliar: «De veia está péssima.»

Mãe: «O outro dia foi tentando, tentando... »

A mãe ajuda a retirar a tenda e pede para segurar a criança enquanto a auxiliar administra a medicação à $\mathrm{J}$.

Auxiliar (falando com a criança): «A mamãe fez a nenem bonitinha...»

Mãe: «Ela só gosta da tia que cuida, não da que dá injeção».

A auxiliar ajeita a criança no berço. A seguir a atendente e a auxiliar saem da enfermaria; imediatamente a mãe descobre a criança inspecionando-a atentamente e cobrindo-a em seguida.

$11 \mathrm{~h}$ - A atendente retorna, manipula prontuários e conversa com a mãe, dando as informações por esta solicitadas. A mãe permanece com a mão sobre a criança, observando-a com ar prescrutador.

11h15m - Atendente: «Você trouxe leite?»

Mãe: «Não, porque acho que o leite secou; deve ser pelo comprimido....

A atendente comenta motivos para o leite secar (conhecimentos empiricos).

$11 \mathrm{~h} 25 \mathrm{~m}$ - Mãe: (olhando a enfermaria contígua pelo visor): «Nossa, tem um menino enorme aí...»

Atendente: «É, tem dois grandinhos.»

$11 \mathrm{~h} 30 \mathrm{~m}$ - A atendente canta e escreve em uma papeleta, enquanto faz comentários sobre problemas culinários com a auxiliar, que aplica medicação intramuscular em outra criança. A mãe de J. observa a auxiliar aplicar a injeção na outra criança enquanto esta dormia e que não é confortada após esse procedimento.

A auxiliar deixa a criança chorando forte, continuando a falar sobre problemas culinários com a atendente.

NOTA: A enfermeira não entrou na enfermaria durante o período da primeira observação.

2a observação: - data: 23 de setembro (quinta-feira) $10 \mathrm{~h} 30 \mathrm{~m}$; magem.

- pessoal: uma auxiliar de enfermagem, uma atendente de enfer-

- criança: sem tenda de oxigênio.

10h55m - Chega a mãe; sorri; observa a criança, encostando no berço; lava as mãos. A criança recebe medicação oral, a atendente oferece água à J. Pergunta à mãe de J. se quer ficar ao lado da criança (com a grade do berço abaixada). A mãe acaricia e observa a criança; 
conversa com outra mãe visitante sobre o soro, sonda nasogástrica e «marcas» na cabeça, em tom muito baixo. Olha desconfiada as observadoras.

$11 \mathrm{~h}$ - Entra a enfermeira; não cumprimenta.

11h01m - A mãe de J. em pé ao lado do berço, acaricia a criança. A atendente do serviço de radiologia entra na enfermaria, aproxima-se do berço de J. e pergunta sorrindo como está a sriança.

11h02m - Retorna a enfermeira, senta e não olha para as mães. Comenta com as funcionárias sobre a mesa que está ruim. Sai novamente. da J.»

11h06m - Retorna a enfermeira e comenta: «Deixa ver a carinha

Aproxima-se do berço, descobre a criança rapidamente; não fala com mãe. Logo em seguida lava as mãos. Não encontra toalha; sai à procura e retorna com papel toalha.

$11 \mathrm{~h} 08 \mathrm{~m}$ - A enfermeira sai novamente. Vai à enfermaria contígua. Retorna, manipula os prontuários, assobiando. Conversa com a atendente que, sentada de costas para as mães, escreve nos prontuários. Falam sobre problemas pessoais (distância do lugar de trabalho, número de conduções que precisam tomar, etc.); dão risadas. A enfermeira conta uma piada e olha para as mães que observam atentamente a conversa, elas também riem da piada. Apesar da conversa amigável, durante todo o diálogo o tratamento da atendente para a enfermeira é de «senhora», e da enfermeira para a atendente é "você». Entra outra atendente que se dirige à enfermeira tratando-a por «chefinha».

$11 \mathrm{~h} 17 \mathrm{~m}$ - Entra uma aluna de enfermagem e conversa com a atendente e a enfermeira. Não cumprimenta as mães. A enfermeira continua fazendo transcrições; a atendente sai.

$11 \mathrm{~h} 22 \mathrm{~m}$ - A enfermeira levanta, observa a enfermaria (recursos materiais).

$11 \mathrm{~h} 25 \mathrm{~m}$ - Entra uma aluna de enfermagem usando máscara e se aproxima da mãe de J. (não explica à mãe o porquê da máscara).

$11 \mathrm{~h} 28 \mathrm{~m}$ - A enfermeira sai da enfermaria. A mãe, calada, permanece em pé ao lado do berço.

\section{Observagão complementar}

No primeiro contato com a enfermeira chefe da unidade, durante nossa conversa, um senhor aproximou-se timidamente. A enfermeira interrompeu a conversa para atendê-lo e indicar a enfermaria onde se encontrava a criança que ele queria visitar - sua filha. Cinco minutos depois, na porta da enfermaria, a enfermeira fala para o pai, com tom de voz elevado e autoritário: "Você tem que vir visitar a nenem... esta é uma unidade de crianças graves e não podemos dar informações por 
telefone. A nenem precisa de visitas da família. Qualquer um pode visitar durante o horário de visitas: tio, avô, compadre... Até agora em quinze dias, é a primeira visita que você faz para ela. Isso não pode. continuar.»

O senhor nada fala; desvia o olhar.

\section{DADOS OBTIDOS DAS ENTREVISTAS}

Ao chegarmos às enfermarias para realizar as entrevistas programadas, perguntamos às mães se poderiam responder a umas perguntas, explicando que estávamos fazendo um trabalho com as mães que visitavam os filhos no hospital. Elas concordaram com a entrevista. Para proporcionar maior privacidade, as entrevistas foram realizadas fora das enfermarias.

a) Entrevista com a mãe de P. - caso 1.

- Como a senhora se sente no hospital, quando vem visitar o P.?

«Tem dias que volto chateada, mas em geral fico tranqüila porque as pessoas cuidam bem dele. Hoje, por exemplo, fiquei chateada porque a mãozinha dele está com uma bolha. Além disso, toda vez que o $P$. precisa internar não preciso ficar a noite toda na fila do Pronto-Socorro; já tem vaga garantida prá ele».

\section{- Como se sente em relação às pessoas que cuidam de seu filho?}

«Me sinto bem. Vejo a Dra. M. todo dia; as atendentes são boazinhas... sempre que faço uma pergunta, se ele está mamando, o peso dele, se fez cocô, ou se está dormindo, elas respondem.»

\section{- E a enfermeira?}

«Não pergunto nada a elas; também já perguntei pras atendentes!»

(Ao ouvir a pergunta a mãe faz um muxoxo com a boca)

\section{- Como se sente quando sai do hospital, após a visita?}

«Me sinto tranqüila, mas sempre fico pensando em casa se ele está dormindo, mamando; essas coisas ... »

b) Entrevista com a mãe de J. - caso 2.

\section{- Como se sente aqui no hospital?}

«Hoje estou triste porque vão trocar os médicos. Vai sair o Dr. C.; ele é ótimo, ressuscitou a J. muito bom tanto para J. quanto para mim. Converso com ele sobre meus problemas; tenho um caroço no seio e ele me encaminhou a outro médico. No outro hospital, só podia ver a criança pelo vidro, as enfermeiras sempre diziam que a criança estava regular. Aqui não; fico perto da J., sei como ela está, converso todos os dias com o Dr. C.; não preciso procurá-lo; ele está todos os dias e me conta como a J. está, se ganhou peso, etc. Não sei, mas ele é dife- 
rente; a gente fica sempre achando que o médico é autoridade e que não se pode chegar perto; com o Dr. C., não é assim.»

filha?

- Como se sente em relação às outras pessoas que cuidam de sua

«São todos muito bons. Cuidam muito bem da J ...; bom, pelo menos sempre quando chego ela está sem xixi e sem sujeira; as enfermeiras são muito boas; ainda hoje falei com a enfermeira que a J. só mama com bico quadrado e ela mudou o bico da mamadeira e escreveu em todos os lugares para as outras saberem. Isto já havia sido dito antes e o bico continuava a vir errado; mas elas também são muitas. Acho que será melhor falar com todas dos outros horários.»

\section{Qual o nome da enfermeira com quem a senhora falou?}

«G., é a que está todos os dias na enfermaria quando chego para a visita da manhã; a que faz as injeções também é boa; conversa sempre comigo; não tenho queixas de ninguém».

\section{- Como se sente quando termina a visita e volta para casa?}

«Muito triste, mas sei que a J. está em boas mãos. Gostaria de visitá-la mais vezes, mas meu marido está desempregado. Gasto $\mathrm{Cr} \$$ $1.000,00$ todos os dias que venho visitá-la; preciso também pensar no meu outro filho que está em casa.»

Observações: - o tom de voz da mãe durante a entrevista, contrariamente ao que acontecia na enfermaria, foi alto;

- a enfermeira G. mencionada pela mãe, é a atendente de enfermagem da enfermaria.

c) Entrevista com a enfermeira chefe. zada?

- O que representa para você a visita dos pais à criança hospitali-

«A visita tem um aspecto bom e um aspecto ruim. É ruim pelo tumulto na enfermaria, mas até que as mães ficaram bem distribuídas nos dois horários que temos agora. Eu acho a visita muito importante para as crianças; é um momento de contato com o ambiente delas. Aqui, por mais que a gente tente, não consegue reproduzir o ambiente $e$ as rotinas do lar; a visita seria também um bom momento para dar uma boa conversada com os pais, quando existir tempo. Vejo a visita para os pais apenas como um momento em que eles procuram informaçōes; por exemplo, se a criança está de alta, quando eles poderão levar a criança para casa, etc.»

- Você disse que a visita dos pais seria um bom momento para conversar com os pais...

«No momento não é possivel pelas nossas atividades que, na verdade, não são desse horário, mas que acabam sendo feitas nesse horário. Mas 
temos intenção de melhorar, vamos aproveitar o horário de visita para colher informações sobre a criança.»

\section{- Que tipo de informacões por exemplo?}

«Sobre o ambiente do lar, condições de saneamento básico; sobre hábitos da criança, por exemplo se usa chupeta, se suga o polegar, se dorme com luz acesa, se para dormir precisa esfregar uma fralda no rosto, se carrega um cobertor, etc.»

\section{- Como você se vê, se percebe, frente aas pais?}

«Nunca tive dificuldades para abordar os pais; é fácil falar com eles. Agora, com as crianças... A partir de um tempo, parei de me envolver com elas; não dava para chegar todo dia chorando em casa, especialmente considerando o tipo de crianças que nós temos.» (Ao falar isto diminui o tom e o ritmo da fala, seus olhos enchem de lágrimas; muda a postura corporal que no início da entrevista era rigida).

- Sabemos que existe limitação para a equipe de enfermagem fornecer informacõos aos pais...

«Todos são proibidos de dar informações, de dar qualquer informação. Sempre foi assim, desde que comecei a trabalhar aqui, há seis anos e meio.»

\section{- De onde veio essa ordem?}

«Não sei de quem veio a ordem, mas não me incomoda; não vejo como sendo problema, para as enfermeiras pelo menos... talvez eventualmente uma enfermeira dê informação. Agora, informaçōes do tipo se a criança mamou, se chorou, etc. tudo bem, podem ser dadas. Mas quando perguntam sobre a diarréia, por exemplo, então encaminhamos para o médico».

\section{d) Entrevista com a enfermeira da unidade.} lizada?

- O que representa para você a visita dos pais à criança hospita-

«O horário de visitas no hospital foi modificado há pouco tempo. No inicio a visita das mães pela manhã não foi encarada com bons olhos; vinham mais mães no periodo da manhã e isso poderia atrapalhar o serviço. Agora, acho que não tem importância porque as mães não atrapalham. Ao contrário, ajudam na alimentação, troca de fraldas... Algumas mães muito ansiosas, fazem perguntas demais; às vezes, a mesma pergunta para funcionários diferentes... Isso chateia (faz expressão de desagrado). Mas, no geral, a presença dos pais nada modifica. Acho que a mãe de uma criança que está em isolamento é ansiosa demais! pergunta demais!... É uma mãe que está descompensada; é uma família que está descompensada.»

e) Entrevista com o auxiliar de enfermagem. 
«Quer que eu seja sincera? Dependendo da criança, elas me irritam, principalmente quando a criança está com soro; eles querem pegar a criança no colo, mexem com ela e no fim a criança perde a veia. Eu sofro também, porque às vezes a criança acabou de ser picada por várias vezes até puncionar a veia... Entendo o que os pais sofrem com isso. Agora, uma criança que não está em soroterapia, nenhum problema; é bom para as crianças.»

\section{- Como você vê a presença dos pais?.}

«Tem alguns casos que me tiram do sério.»

\section{- Alguns casos a tiram do sério ... Por exemplo?}

«Por exemplo, uma criança que não está em soroterapia e que tem ima medicação endovenosa; é difícil conseguir puncionar a veia com os pais por perto; eles ficam nervosos, se irritam; eu entendo, isso aconteceria comigo também; mas me irrito muito...»

- Como você se vê frente aos pais?

«Segura; tento entender aqueles deprimidos, quietos, que sofrem mais; mães de rua são difíceis, não entendem; não é impossível, mas é muito dificil. As outras, com um bom papo, a gente consegue.»

\section{- E quando os pais solicitam informações?}

«Somos proibidos de dar informações; sempre encaminhamos para o médico ou enfermeira, às vezes falamos sobre alimentação, mas corre-se o risco de dar informações erradas. Problemas administrativos encaminhamos para a enfermeira; perguntas sobre o estado da criança, tratamentos etc., para o médico; ele tem jeito com os pais.»

\section{f) Entrevista com atendente de enfermagem - (caso 1).} lizada?

O que representa para você a visita dos pais à criança hospita-

«Acho muito bom. Para mim a presença dos pais não atrapalha o serviço; ao contrário, vejo que elas sentem prazer em cuidar da criança, dão carinho, conversam ... Acho isso importante. Fico chateado quando vejo uma mãe que não cuida do filho; já vi uma mãe que ficava de braços cruzados em frente à criança sem fazer nada; eu também não sodia fazer nada; tinha vontade de mandá-la pegar a criança, cuidar dela, mas não podia ...

g) Entrevista com atendente de enfermagem - (caso 2). lizada?

- O que representa para você a visita dos pais à criança hospita-

«Eu acho a visita boa para as crianças e também para os pais. As crianças precisam da família.» 


\section{- Como você vê a presença dos pais?}

«Olha, têm mães interessadas e outras desinteressadas. Para as interessadas eu gosto de falar, ajudar, responder perguntas que eu posso responder; as desinteressadas me incomodam.»

\section{- Quando você considera que uma mãe é interessada?}

«Bom, quando faz perguntas sobre a criança, repara nas mudanças na criança de um dia para outro, dá cuidado à criança, dá carinho para o filho. As desinteressadas não fazem nada, ficam quietas, só olhando... Já pensei que também poderia ser medo... A presença das mães não altera a forma em que cuido das crianças, ainda que seja mãe desinteressada... Eu pretendo ser uma mãe interessada por meu filho; as crianças agora parecem diferentes para mim; acho que estou mais sensivel.»

(Observação: está grávida do primeiro filho).

\section{ANALISE DOS DADOS}

\begin{tabular}{l|l}
\hline Dados Significativos & Análise \\
\hline
\end{tabular}

\section{CASO 1}

- Os poucos contatos havidos entre a equipe de enfermagem e a mãe foram de curta duração e inconseqüentes.

- A única vez que a enfermeira abordou a mãe foi de forma indireta, ou seja, chamando pelo nome da criança, que não podia responder.

- A mãe considera-se satisfeita com a assistência que a criança vem recebendo; valoriza os cuidados físicos que a criança recebe; entretanto, mostrou desagrado pelo atraso da mamadeira no $2^{\circ}$ dia da observação.

\section{CASO 2}

- A mãe mostra-se receosa de tocar na criança. Entretanto, quando as funcionárias saem da enfermaria, ela descobre a criança e a examina cuidadosamente.
- A escassa comunicação enfermagem/mãe pode indicar desvalorização, por parte da equipe de enfermagem, da visita, como oportunidade para interação efetiva com os pais.

- Com a ordem para a criança retornar à enfermaria - "sua casa" estaria a enfermeira querendo mostrar que, no hospital, a mãe tem de: se submeter às normas e rotinas da instituição, perdendo seu direito sobre a criança?

- A contradição é evidente. A assistência à saúde da criança é vista como uma dádiva e não como um direito. Até que ponto ela conhece seus direitos?

- Seria por medo de năo saber lidar com a criança? Fatos posteriores negaram esta hipótese. Levanta-se a possibilidade de ser repreendida pela equipe ou de sentir-se destituída de seus direitos de mãe ante a presenca do pessoal hospitalar. 
- A auxiliar aplica medicação intramuscular conversañdo carinhosa mente com a criança cuja mãe estava presente. Em outra criança no entanto, cuja mãe estava ausente, ela o faz enquanto a criança dormia e não a conforta após o procedimento.

- A enfermeira, em vinte e oito minutos, entrou e saiu cinco vezes da enfermaria. Manipula prontuários, olha o carro de medicação, traz papel toalha, etc. Em nenhum momento interage com a mãe.

- A postura da enfermeira em relação ao ambiente é descontraída. Assobia, conversa com as funcionárias sobre problemas pessoais e conta piadas. Apesar disso, o tratamento de funcionário para enfermeira é de respeito, ou seja, elas a tratam por senhora.

- A mãe, embora com a idéia de que - médico é autoridade, considera-se valorizada pelo médico da filha que diariamente lhe informa sobre $a$ estado da criança.

Equipe de enfermagem - dados obtidos das entrevistas

\section{a) Enfermeira Chefe}

- Considera que a visita tem aspectos pasitivos e negativos: positivos, para a criança que precisa de sua família, e para os pais fazerem perguntas. Negativos porque tumultuam a enfermaria.

- Acha que a visita seria uma oportunidade para "dar uma boa conversada" com os país sobre os hábitos da criança com a finalidade de tentar reproduzir no hospital o ambiente do lar da criança.

- Diz não ter dificuldades para abordar os pais. Considera fácil falar com eles.

- A limitação da equipe de enfermagem de fornecer informaçōes é aceita sem contestações.
-. Durante a entrevista a auxiliar afirma que a presença dos pais não modifica sua forma de tratar a criança. A que atribuir, então, esta diferença de atitude?

- As ações predominantemente administrativas não permitem que execute as assistenciais, o que torna patente o desvirtuamento das funções da enfermeira.

A relação dominação/submissão entre a enfermeira e os outros membros da equipe de enfermagem é evidente.

- Observa-se claramente a representação de papéis institucionalizados, com o mito de medicina e da figura do médico ainda persistindo na população.

- Desconhecimento da importancia das ações que deveríam ser desenvolvidas nesta circunstância.

- Chama a atenção a contradição existente entre o discurso e a ação desta profissional. $O$ "puxão de orelhas" em público que deu no pai que não visitava a filha assim o demonstra.

- A relação dominação / subraissão existente entre os profissionais da saúde e a clientela mais uma vez se torna patente.

- A não contestação de normas institucionalizadas evidencia a alienacão do profissional enfermeiro dentro do sistema. 
b) Auxiliar de enfermagem

- A depender do estado da criança, com medicação endovenosa ou não, a presença dos pais no horário da visita a irrita.

- Destaca as "mães de rua" como sendo mais dificeis de lidar.

- Quando interrogada pelos pais sobre problemas administrativos, encaminha-as para a enfermeira; sobre tratamento, para o médico.

c) Atendente de enfermagem

- Percebe as mães como "interessadas e desinteressadas". Estas últimas a incomadam; não fala com elas. Pretende vir a ser uma mãe interessada; está grávida e agora as crianças parecem ter mudado para ela.
- Supervalorização do próprio trabalho. Não se poderia ensinar aos pais como lidar com uma criança que está em soroterapia?

- Estereótipo! Preconceito?

- A representação de papéis institucionalizados é clara, cabendo à enfermeira somente as questões de caráter administrativo.

- Observa-se a história individual influenciando a forma de perceber os outros.

\section{CONCLUSOEES}

A análise dos dados obtidos neste estudo permitiu-nos chegar às conclusões que seguem, válidas para ambos os casos.

- As interações da equipe de enfermagem com as mães visitantes fcram escassas, de curta duração e não efetivas.

- O tipo de relação social entre a equipe de enfermagem e pais na visita à criança hospitalizada que se apresentou como predominante na situação estudada foi a relação dominação/submissão.

- Nas relações sociais entre a equipe de enfermagem e as mães visitantes houve reprodução da lógica do sistema com sua divisão em classes sociais distintas.

- Nas relações sociais entre a equipe de enfermagem e as mães na visita ao filho hospitalizado existiu a presença de estereótipos comportamentais, ou seja, dissociação entre a teoria e a prática, tanto em relação à equipe de enfermagem, quanto às mães que fizeram parte do estudo, com o mito da medicina e da figura do médico presentes na situação.

- O profissional enfermeiro apresentou-se omisso em relação à atividade própria de sua profissão. As ações que desenvolve são determinadas e reproduzem a ideologia da instituição. Isto sequer é questionado, o que demonstra sua alienação dentro do sistema.

- O contexto sócio-cultural e histórico dos personagens envolvidos exerceu influência na situação problema estudada. 
Quanto às lacunas do trabalho observamos a necessidade de maior aprofundamento nas seguintes questões:

- as respostas dadas pelas mãos às perguntas formuladas seriam as mesmas se fossem feitas após a alta hospitalar, e a entrevista fosse realizada no domicilio?

- qual a origem da proibição de que a equipe de enfermagem informe sobre o estado da criança? E uma norma documentada ou apenas uma ação institucionalizada?

Em relação ao grupo de trabalho, houve uma verdadeira reavaliação de atitudes passadas e, não sentimos receio em afirmar, algumas delas com certeza nunca mais se repetirão sem que, pelo menos pensemos antes em alternativas de ação.

NEIRA HUERTA, E. del P.; MADEIRA, L.M.; MIRANDA, M.M.; GARCIA, T.R. Social relations between the nursing team and the parents of hospitalized children. Rev. Esc. Enf. USP, São Paulo, 20(1):55-69, 1986.

By means of partially structured interviews and assistematic observation, the authors attempt to identify the types of social relations that occur between the nursing team and the parents visiting the hospitalized child.

\section{REFERENCIAS BIBLIOGRAFICAS}

1. BRIGHT, F. The pediatric nurse and parental anxiety. Nurs. Forum, Hillsdale, 4(2):30-47, May 1865.

2. ROY, C. Rol cues for the mother for the hospltallzed child. In: AMERICAN NURSE'S Association. ANA Clinical Sessions. 1968. New York, Appleton - Century Crofts, 1968. p.199-206.

3. SMIthermaN, C.H. Parents of hospitalized children have needs, too. Am. J. Nurs., New York, 79(8):1423-4, Aug. 1979. 